\title{
Servikal miyelopati ve radikulopati; ayırıcı tanı
}

\section{Differential diagnosis of cervical myelopathy and radiculopathy}

\author{
Sinan Karaca, Ahmet Öztermeli
}

Fatih Sultan Mehmet Eğitim ve Araştırma Hastanesi, Ortopedi ve Travmatoloji Kliniği, İstanbul

\begin{abstract}
Boyun ve bel ağrısı, ortopedik poliklinik başvuruları arasında en sık olandır. Boyun, omuz ve kolda ağrı yapabilecek birçok neden vardır. Dolayısıyla, bir hastanın birden fazla tanı alması çok sık görülür. Eksiksiz bir tanı koyabilmek için tam bir öykü alınmalı ve muayene çok dikkatli yapılmalıdır. Omurga normal fonksiyonunu yapmazsa, mekanik stimülasyon miyelopatik semptomlara neden olabilir. Servikal miyelopatide klinik problem üst ekstremite de olsa bile, alt ekstremite hiperrefleksi ve spastisite açısından muayene edilmelidir. Hasta yürütüldüğü zaman, miyelopatik ise uzun adımlı ve dengesiz spastisite yürüyüşü görülebilir. Miyeloradikülopati, hem üst hem de alt motor nöron semptomlarının birlikte görüldüğü klinik bir durumdur; güçsüzlük, ağrı ve spastisitenin birlikte olduğu karışık bir klinik tablo mevcuttur. Güçsüzlük gibi alt motor semptomları üst ekstremitede gözükür ve üst servikal bölge stenozundan kaynaklanır. Spastisite ve koordinasyon bozukluğu gibi üst motor nöron semptomları, genel olarak alt servikal bölge stenozuyla ilişkilidir. Bu derlemede amaç, servikal miyelopati ve miyeloradikulopatinin ayırıcı tanısını sistematik bir şekilde ele almaktır.
\end{abstract}

Anahtar sözcülkler: servikal miyelopati; radikülopati; ayırııı tanı
Neck and lower back pain are the most common among orthopedic outpatient clinic applications. There are many causes of neck, shoulder and arm pain; that's why a patient could frequently get multiple diagnoses. Appropriate anamnesis and careful physical examination are necessary for a precise diagnosis. Mechanical stimulation could cause myelopathic symptoms unless the spine maintains its normal function. Although the clinical problem is in the upper extremity in cervical myelopathy, appropriate lower extremity examination focused on hyperreflexia and spasticity is necessary. When the patient walks, unbalanced spastic gait and myelopathic long-stride can be observed. Myeloradiculopathy is a clinical situation that can cause both lower and upper motor neuron symptoms. There is a mixed clinical picture of weakness, pain, and spasticity. Lower motor neuron symptoms like weakness are seen in the upper extremity and caused by upper cervical region stenosis. Upper motor neuron symptoms like spasticity and incoordination are usually related to stenosis of the lower cervical region. The aim of this study is to review systematically the diagnosis of the cervical radiculopathy and myelopathy.

Key words: cervical myelopathy; radiculopathy; differential diagnosis
B oyun ve bel ağrısı, ortopedik poliklinik başvuruları arasında en sık olandır. Boyun, omuz ve kolda ağrı yapabilecek birçok neden vardır. Bir hastanın birden fazla tanı alması çok sık görülür. Eksiksiz bir tanı koyabilmek için tam bir öykü alınmaIı ve muayene çok dikkatli yapılmalıdır. Tanı konulan hastalarda semptomların ana nedenini bulmak çok önemlidir.

\section{Servikal Miyelopati}

Klinik problem üst ekstremite de olsa bile, alt ekstremite hiperrefleksi ve spastisite açısından muayene edilmelidir. Hasta yürütüldüğü zaman, miyelopatik ise uzun adımlı ve dengesiz spastisite yürüyüşü görülebilir. Hızlı adımlarla ve uzun mesafe yürüyen bir hastanın yürüyüşü bozulma eğilimindedir. Miyelopatili hastanın aile bireyleri, o kişinin yürürken düzenli olarak onlara çarptığını ifade eder. ${ }^{[1]}$

\section{Miyeloradikülopati}

Miyeloradikülopati, hem üst hem de alt motor nöron semptomlarının birlikte görüldüğü klinik bir durumdur. Güçsüzlük, ağrı ve spastisitenin birlikte olduğu karışık bir klinik tablo mevcuttur. Güçsüzlük gibi alt

- İletişim adresi: Op. Dr. Sinan Karaca, Fatih Sultan Mehmet EAH, Ortopedi ve Travmatoloji Kliniği, E5 karayolu üzeri, İçerenköy, Ataşehir, İstanbul Tel: 0216 - 5783000 e-posta: mdsnn@hotmail.com

- Geliş tarihi: 5 Nisan $2017 \quad$ Kabul tarihi: 5 Nisan 2017 
motor semptomları üst ekstremitede gözükür ve üst servikal bölge stenozundan kaynaklanır. Spastisite ve koordinasyon bozukluğu gibi üst motor nöron semptomları, genel olarak alt servikal bölge stenozuyla alakalıdır. Bu sendrom, hem kord hem de sinir kökü kompresyonu olan hastalarda sık görülür. ${ }^{[2]}$

\section{İnstabilite}

Postürü sağlamak ve nöral elemanları korumak omurganın görevleridir. Servikal instabiliteye birçok hastalık neden olabilir. Omurga normal fonksiyonunu yapmazsa, mekanik stimülasyon miyelopatik semptomlara neden olabilir. Servikal omurga normal diziliminden sublukse olursa, kord ve sinir kökleri kompresyona uğrayıp irrite olabilir.

\section{C3 Radikülopati}

Üçüncü servikal kök, dejeneratif hastalık nedeniyle çok nadir olarak kompresyona uğrar. Bunun nedeni, sınırlı C2-C3 disk hareketidir. Bu kökün dermatomu, boyun oksiput ve kulaklara uzanır. Bu kökün net bir motor fonksiyonu olmadığı gibi, hissizlik çok nadir görülür. Baş ağrısı C3 radikülopati ile karıştırılabilir. ${ }^{[3-5]}$

\section{C4 Radikülopati}

C3-C4 diski C2-C3 diskinden daha fazla harekete sahiptir; dolayısıyla radiküler ağrıya daha çok rastlanır. C4 kök ağrısı boynun kökünde, omuz mediyalinde ve skapulanın alt tarafında hissedilir. C4 sinir kökünün tam olarak motor fonksiyonu yoktur; ancak ağrı boyun ekstansiyonu ile provoke olur. Bu dördüncü kök diyafram fonksiyonunu kontrol eder, ancak diyafram fonksiyonu nadir olarak etkilenir. ${ }^{[3-5]}$

\section{C5 Radikülopati}

C4-C5 seviyesinde fitıklaşma, alt seviyelere göre daha az görülür. C5 sinirinin duyusal alanı, boynun tabanından omuzun üstüne, oradan da kolun üst lateraline uzanır. Omuz patolojileriyle ayrımı çok zordur. Servikal hastalıkların omuz hastalıklarından ayrımını yapabilmek için muayene esnasında dikkatlice tam bir omuz muayenesi yapılmalıdır. Omuz muayenesinde internal-eksternal rotasyon ve rotator manşet güç testleri mutlaka yapılmalıdır. Bazı C5 kök patolojisine sahip hastalarda, radiküler ağrının omuz hareketlerini kısıtlaması sonucunda donuk omuz gelişebilir. Motor tutulum sonucu, omuz abduksiyonu (deltoid) ve dirsek fleksiyonu (triseps) etkilenir. Bu durum, klinik olarak akut rotator manşet yırtığını taklit eder, ancak omuzda ağrı ve hassasiyet yoktur. Deltoidin tam paralize olması, hastalar kollarını başlarını üzerine kaldırmadıkları için, hastaların günlük yaşamsal aktivitelerini etkiler.
Dikkatli bir muayene ile, omuz eksternal rotasyonunda zayıflık saptanabilir (infra-supra spinatus). Muhtemel biseps refleksinin suprese olması nedeniyle, C5 kök lezyonlarında biseps güçsüzlüğü saptanabilir. ${ }^{[3-5]}$

\section{C6 Radikülopati}

C5-C6 diski seviyesi, C6-C7 diski ile birlikte dejeneratif disk hastalığında en fazla etkilenen seviyedir. Altıncı kök lezyonlarının ağrısı boynun tabanından başlar, biseps kası boyunca devam eder ve önkol lateralinde seyreder; el ve el parmaklarının radyal taraf dorsumunda sonlanır. Biseps kası boyunca hassasiyet görülebilir. Klinik durum, genel olarak kolun proksimalinde ağrı ve elde hissizliktir. ${ }^{[3-5]}$

\section{C7 Radikülopati}

C6-C7 seviyesinde, disk herniyasyonu ve stenoz sıklığı nedeniyle $C 7$ radikülopatisi çok sık görülür. Hastalar, omuzun dorsalinde triseps kası boyunca ve önkolun dorsolateralinde ağrı tanımlar. Triseps refleks kaybı, C7 radikülopatisi ve disfonksiyonu için göstergedir. Sportif faaliyetleri olan ve gün içerisinde başının üstüne uzanarak iş yapan hastalar, triseps güçsüzlüğünden yakınabilirler. Muayene ederken, hastanın triseps güçsüzlüğünü kompanse etmek için humerusu iç rotasyona almamasına dikkat edilmelidir. C7 kökü pektoralis major kasının bir kısmını innerve ettiği için, humeral adduksiyon test edilmelidir. Pronator, ekstansör dijitorum, latismus dorsi ve fleksör karpi radyalis, etkilenen diğer kaslardır. ${ }^{[3-5]}$

\section{C8 Radikülopati}

C7-T1 seviyesinde fitıklaşma çok nadir görülür. C8 sinir kökü, önkolun ve elin ulnar tarafının duyusunu alır. Ulnar sinir lezyonu ile aynı hissizlik ve ağrı tablosu vardır. C8 sinir kökünün muayenesi küçük kaslarla yapilır. Fleksör dijitorum profundus ve superfisialis kasları tarafından sağlanan parmak fleksiyonu, sekizinci kökün kontrolü altındadır. İnterossei gibi intrensek kaslar parmak abduksiyonunu kontrol eder ve C8-T1 tarafından innerve edilir. Motor fonksiyon kaybında tutma gücü azalır. Birinci dorsal interoosseöz kasın zayıflığından dolayı, anahtar çevirmede ve küçük objeleri tutmada zorluk olabilir. ${ }^{[3-6]}$

\section{KLINIK SENDROMLAR}

\section{Disk Herniyasyonları}

Servikal disk hernisinin klinik prezantasyonu, bağI olduğu bölgeye göre değişir. Genel olarak, hastalar boyun ve etkilenen köke bağlı olan dermatomda ağrı hissederler; ağrının sınırlamasından dolayı, güçsüzlük çoğu zaman hemen anlaşılmaz. 
Bazı hastalarda, hastalıklı taraftaki forameni açmak için karşı tarafa doğru tortikollis ve düşük omuz saptanır. Servikal omurganın ekstansiyonu ağrıyı arttırır. Bu hastalarda omuzlar karakteristik olarak abduksiyonda, önkol başın üzerinde dinlenme halindedir. Bu pozisyonda, servikal omurga lateral fleksiyona gelir ve etkilenen nöral foramen açilır. Rutin nörolojik muayene, etkilenen sinir kökünde karakteristik değişiklikler gösterir. ${ }^{[7-9]}$

Çok büyük fitıklaşmış diskler miyelopatik bulgular verebilir. Bu, genellikle konjenital dar kanalı olan ve disklerinde halen çok fazla materyal olan genç hastalarda görülür. Disk fitıklaşması orta hatta ise, blokaj seviyesinin altında güçsüzlük ve spastisite bulguları vardır. Eğer fragman kanalın bir tarafında daha fazla ise, o zaman miyelopatik bulgulara radiküler kol ağrısı ve alt motor nöron semptomları eklenebilir. ${ }^{[10]}$

\section{Servikal Spondilitik Stenoz}

Servikal stenoz neden olan dejeneratif değişikliğe sahip hastalar, en sık miyelopatik bulgular ile karşımıza çıkarlar. Disk dejenerasyonu; yükseklik kaybı, annular bulging ve spinal kanal daralması ile sonuçlanır. Fasetler dejenere olunca, foramen ve kanal daralması spinal kordu ve sinir köklerini deforme edebilir. Diskin yüksekliğinin kaybolması, teleskopik etki ile dorsal bağların kanalı çevresel olarak daraltmasına neden olur. Instabilite, hassas spinal korda dinamik kompresyon yapabilir. Varolan konjenital darlık, daha genç yaşlarda miyeloradikülopatik bulgulara yol açabilir. ${ }^{\text {[11-13] }}$

İleri dejeneratif değişiklikleri ve dar spinal kanaI olan hastalarda santral kord sendromunun klasik nedeni, servikal omurgayı ekstansiyona getirecek bir düşmedir. ${ }^{[13]}$

Posterior longitudinal bağ ossifikasyonu en sık Asya'da, özellikle Japonya'da görülür. Bağ, kortikal kemik ile birlikte ossifiye olunca büyür ve spinal kanal içinde yer kaplar. illk başlarda sessiz bir kompresyon olduğu için, hastalarda miyelopatik semtomlar çok azdır. Bu hastaların omurgaları katıdır ve aşırı hareketlerin neden olabileceği mekanik stimülasyonlara karşı kendisini korur. Miyelopatik semptomlar yavaş yavaş gelişebileceği gibi, aniden bir travma sonrasında da gelişebilir. Erkek ve kadınlar arası etkileşim eşit orandadır. Kortikal kemik kompresyona neden olduğu için, tanı koymada bilgisayarlı tomografi manyetik rezonanstan daha değerlidir. ${ }^{[14-15]}$

\section{Omuz}

C5 radikülopati ile en çok karışan ağrı, akromiyonun altından geçen rotator manşet kompleksinin sıkışmasına bağlı olarak ortaya çıkan ağrıdır. Genellikle, ağrıya bağlı olarak deltoid kasında ve rotator kaslarda güçsüzlük vardır ve bu durum omuzda eklem hareket kısıtlılığına yol açabilir. Ağrı önkola doğru yayılarak kliniği maskeleyebilir. Servikal muayene esnasında ayrıntılı bir omuz muayenesi şarttır. Omuz ve boyun patolojilerini ayırt etmede, omuzun radyolojik görüntülemesi ve eğer gerekirse tanısal enjeksiyon uygulanabilir. Bu iki durum aynı anda (simültane) olabilir ve ayrı ayrı tedavi edilmelidir. ${ }^{[6,16]}$

\section{Dirsek}

Önkol kaslarının dirsekte yapışma yerlerinde meydana gelen tendinit, radiküler ağrıyı taklit edebilir. Ağrı, omuz ve el bileğine doğru yayılabilir ve servikal patolojilerle birlikte olabilir. Zorlamalı el bilek ekstansiyonu ve supinasyonu sırasında epikondile uygulanacak palpasyon hastada ağrıya neden olur. Nörolojik durumları ayırt etmek için tanısal enjeksiyon kullanılabilir. Aktivite modifikasyonu ve breysleme, tanı koymada ve tedavi etmede yardımcı olabilir. ${ }^{[16]}$

\section{Tümörler}

Birçok yapının tümörü, boyun ve kolda ağrıya neden olabilir. Ağrı, lezyonun yeri ve karakterine bağlı olarak değişebilir. İyi huylu tümörler, vertebral kollaps ve deformiteye yol açarak nörolojik yapılara kompresyon sonucunda klinik sunumlarını kötüleştirebilir.

Osteoid osteoma, lokal ağrıya neden olur ve ağrısı NSAi (non-steroid anti-inflamatuvar) ilaçlar ile rahatlar. Osteoblastoma, dorsal elemanları tutar ve nadir olarak nörolojik semptomlara yol açar. Eozinofilik granüloma, vertebra planaya yol açabilir; ancak genellikle aksiyel boyun ağrısına yol açar.

Dev hücreli tümör ve anevrizmal kemik kisti, büyük yumuşak doku kitlesi ile karakterizedir ve bundan dolayı spinal korda bası yaparak nörolojik semptomlara yol açabilir. Adelosan yaş grubunda dorsal elemanlardaki osteokondromanın hızlı büyümesi, ağrının nonradiküler karakterde olmasına yol açabilir. ${ }^{[7]}$

Uni-radiküler ağrı birçok iyi huylu tümörde gözlenebilir. Duyusal kökten kaynaklanan schwannoma'lar genellikle intraduraldır ve genel olarak unilateral kök ağrısına yol açar. Nörofibromatozis gibi birden fazla lezyon varsa, ağrı multi-radiküler olabilir. Oblik filmlerde, bu lezyonların foramenleri daralttığı görülebilir. Servikal omurganın menenjiyomu, genellikle orta yaş kadınlarda saptanır ve benzer kliniği vardır. ${ }^{[6]}$

Malign lezyonlarda, derin yanma gibi mekanik olmayan ağrılar vardır. Bu hastalarda ağrı, geceleri uyutmaz ve hastalar tam rahat bir pozisyon bulamazlar. $\mathrm{Bu}$ hastalar muayene olurken, uzun süre aynı yerde oturamazlar. Gündüz duyusal giriş fazla olduğundan 
dolayı, hastalar ağrıyı tolere edebilirler. Lezyon büyüdükçe, kemik yıkımına bağlı olan ağrılar radiküler ve miyelopatik ağrılara dönüşebilir. Bu değişiklik aniden olur ve vertebral kollaps gelişirse, bu durum katastrofobiktir. Malign tümöre sahip bir hastada omurga ağrısı başlarsa, mutlaka sintigrafi ile metastaz taraması yapılmalıdır. ${ }^{[17]}$

Ekstraspinal maligniteler, servikal disk hernisini taklit ederek omuz ve boyun ağrısına neden olabilir. Omuzun herhangi bir yerindeki lezyon, biyomekanik anormallik ve ağrı ile hareket inhibisyonuna neden olarak güçsüzlüğe yol açabilir. Akciğerin apeksini tutan akciğer tümörü, buna klasik bir örnektir. Tümör, direkt olarak büyüyerek brakiyal pleksusu invaze edebilir ve rutin akciğer filminde saptanamayabilir. Bu hastalarda; omuzda güçsüzlük, ağrı ve Horner sendromu birlikte görülür. Farinks ve üst mediastenin diğer lezyonları, omurgaya, brakiyal pleksusa ve göğüs kafesine invaze olabilir. ${ }^{[18]}$

Kafa içi lezyonlar, servikal radiküler ağrıları taklit edebilir. Hastada üst motor nöron semptomları varsa, muayene eden kişi beyni sorunların kaynağı olarak düşünmelidir.

\section{Brakiyal Pleksopati}

Omuzun ani depresyonu ve boynun ters tarafa doğru lateral fleksiyonuna neden olan yüksek enerjili motosiklet kazaları, brakiyal pleksus gerilme yaralanmasına neden olabilir. Bu durumda, tek bir sinir kökü etkilenebilir; aynı zamanda multipl yaralanma da olabilir. Birçok sinirsel yaralanmada olduğu gibi, akut yaralanma sonrası refleks sempatik distrofi görülebilir. Kurşunlanma, bıçaklanma veya meme kanseri sonrası yapılan radyoterapi, brakiyal pleksopatinin diğer bazı nedenleridir. İyileşme ve klinik süreç, mevcut yaralanmanın ağırlığı ile ilişkilidir. ${ }^{[19]}$

\section{Üst Ekstremite}

\section{Torasik outlet sendromu (TOS)}

TOS, hem vasküler hem de nörolojik semptomları olan bir durumdur. Vasküler semptomlar, subklaviyan arter veya aksiller arter ve bu arterlere eşlik eden venlerin kompresyonu ile ilişkilidir. Nörolojik semptomlar, C8 ve T1'in kompresyonu ve elin ulnar tarafının etkilenmesinden kaynaklanır. Servikal birinci torasik kaburga, klavikula gibi kemiksel yapılar ile skaleneus antikus, pektoralis minör gibi kasların sıkıştırılması nedeniyle semptomlar oluşur. Vasküler TOS'ta güçsüzlük olmadığı için, TOS servikal radikülopatiden farklıdır. Muayenede, kollarda asimetrik nabızlar ölçülür. Bazı hastalarda; arter klavikula ile birinci kaburga arasına sıkışırsa, hissizlik, güçsüzlük, parestezi olabilir. Hastaların semptomları, elleri yukarıda çalışırken provoke olur. Kollar aşağı inince, hasta rahatlar; boynunu etkilenen tarafa çevirirse nabız azalır ve bu da subklaviyan arter kompresyon bulgusudur. [20,21]

Nörolojik TOS, eldeki intrensek kasların atrofisi (en fazla tenar kaslar) ve güçsüzlügü ile karakterizedir. Nörojenik TOS ile ilişkili olarak, servikal kaburga veya elonge $C 7$ transvers proses gibi birçok anatomik anomali vardır. Semptomlar kadınlarda daha fazladır. Nörolojik semptomların kökeni proksimalde olduğu için, semptonlar ulnar nöropatiden daha belirgindir. Ulnar nöropatide duyusal değişiklikler yüzük parmağında ikiye bölünürken, TOS'ta bölünmez. TOS'ta, lateral tenar atrofi gibi median sinir kompresyon bulguları da saptanabilir. C8-T1 radikülopatisine olan interossei kas tutulumu TOS'ta daha azdır. Nörojenik TOS'ta, elektromiyografide anormallikler saptanabilir. ${ }^{[21]}$

\section{Dorsal skapular sinir sıkışması}

Dorsal skapular sinir, brakiyal pleksusun üst trunkusundan, C8 sinir kökünden kaynaklanır. Skaleneus medius kası içinden geçer ve bu noktada klinik durum oluşabilir. Bu sinir, rhomboid kasın motor fonksiyonunu sağlar. Bu sinir sıkışırsa, kola yayılan ağrı saptanabilir. Cerrahi dekompresyon nadiren endikedir. Omuz kaslarının kuvvetlendirilmesi ile tedavi edilir. Kamçılama tarzı yaralanmada traksiyon oluşabilir. ${ }^{[5]}$

\section{Uzun Torasik Sinir}

Beşinci ve altıncı servikal kaslardan köken alır ve nadiren skalenius medius kası içine girer. Bu dala, kası geçtikten sonra C7 kökünden gelen bir dal katılır. Serratus anterior kasının motor fonksiyonunu sağlar. Fonksiyon kaybı ile kanat skapula saptanır. Skapula stabilize edici egzersizler ve sinirin iyileşmesini beklemek, tedavi yöntemidir. ${ }^{[5]}$

\section{Median Sinir}

\section{Pronator sendrom}

Proksimal volar önkolda ağrı, radyal üç ve yarım parmaklarda semptomlar görülür. Anterior interosseöz sinirin dallanması proksimalde baskı olduğu için median sinir gibi etkileri vardır. C6-C7 radikülopatisine benzer duyusal semptomları vardır. Ancak, triseps el bilek ekstansörleri ve fleksörleri etkilenmez. ${ }^{[5]}$

\section{Anterior İnterosseöz Sinir}

Median sinirin saf motor dalıdır. Önkolda, hareketle artan ve istirahatle azalan ağrı vardır. FPL (flexor pollicis longus), FDP (flexor digitorum profundus) ve pronator 
kuadratusta kurvetsizlik vardır. Genel olarak, kompresyona neden olan bir patoloji yoktur. Bu nedenle, cerrahi araştırma en proksimalden başlar ve AIS boyunca derin kompartmana kadar yapilır. En sık fleksör dijitorum kasının orijininde sıkışma olur. ${ }^{[22]}$

\section{Karpal tünel sendromu}

Median sinirin karpal tünelde sıkışması ile oluşur. Elin güçsüzlüğü, parestezi, hipoestezi ve ağrı en sık semptomlardır. PHALEN testi veya TINNEL işareti ile tanı koyulabilir. Duyusal semptomlar C6-C7 radikülopatisini taklit edebilir. İleri evrelerde tenar güçsüzlük T1 radikülopatisini taklit edebilir. Ancak, birinci interosseöz ve hipotenar kaslar ulnar sinir tarafindan innerve edildiklerinden dolayı sağlamdır. ${ }^{[7]}$

\section{Ulnar sinir sıkışması}

En sık dirsekte, kübital tünelde sıkışır. Ağrı, dirsek mediyalinden başlar, önkol ulnar tarafta devam eder, 4. ve 5. parmağa kadar ulaşır. C8-T1 radikülopatisinden ayrım gerektirir. FPL, tenar kaslar, 2. ve 3. parmağın fleksörlerinin güç muayenesinde sonuç iyi ise, ulnar sinir sıkışması değildir. ${ }^{[23]}$

Ulnar sinirin dorsal kutanöz sinir dalı önkolda ayrılır. Dolayısıyla, bu Guyon kanalı sendromunda elin ulnar tarafının duyusal muayenesinde bulgular normaldir. Sinir, kanalın içinde derin motor ve duyusal dallara ayrilır. Hipotenar interosseöz ve adduktor pollisiste motor zaafa uğrar. ${ }^{[23]}$

\section{Radyal sinir sıkışması}

Önkolda, ekstansör kas grubunda ağrı tanımlanır. Dirsek tam fleksiyonda, el bileği nötral pozisyonda iken ağrı artar. El bileği fleksiyonu ve önkolun pronasyonu alternatif manevralardır. C7 radikülopatisinden triseps tutulumu olmadığından yapılır. ${ }^{[5]}$

\section{Travma}

Travma, birçok nedenle miyelopatiyi tetikler. Genel olarak; spinal kanal daralabilir, nörolojik elemanlar deforme ve damarsal yaralanma olabilir. Hiperekstansiyon sonrası spinal kord, ventral osteofitler ile dorsal ligamentum flavum arasında sıkışır ve santral kord sendromu oluşur. Bazı hastalarda, dorsal bağ yaralanması veya vertebral kırık atlanabilir. Bu hastalarda, sürekli kord kompresyonu ve irritasyonuna bağlı olarak miyelopatik semptomlar saptanabilir. Bu tür durumları saptamada dinamik filmler daha başarılıdır.

Oksipitoservikal bileşke çok dikkatli şekilde incelenmelidir. Dikkatli bakılmaz ise, dens psödoartrozu gibi durumlar atlanabilir. İnstabilitesi olan hastalarda, romatoid artrit veya diğer inflamatuvar hastalıklar göz önünde bulundurulmalıdır.

\section{TARTIŞMA}

Hastanın öyküsü ve eksiksiz bir fizik muayene, doğru tanı için anahtardır. Tüm bu klinik durumlar çok nadir olmasına rağmen, hepsi olabilir. Her zaman, bir hasta için birden fazla hastalığa aynı anda sahip olma olasılığı vardır. Servikal görüntülemesinde yapısal bir lezyon olmayan hastalarda tıbbi nedenler araştırılmalıdır. Tüm bu hastalar için doğru tanıyı koymak çok önemlidir.

\section{KAYNAKLAR}

1. Lim MR, Huang RC, Wu A, Girardi FP, Cammisa FP Jr. Evaluation of the elderly patient with an abnormal gait. J Am Acad Orthop Surg 2007;15(2):107-17.

2. Kikuchi S, Macnab I, Moreau P. Localisation of the level of symptomatic cervical disc degeneration. J Bone Joint Surg $\mathrm{Br}$ 1981;63-B(2):272-7.

3. Bogduk N, Windsor $M$, Inglis $A$. The innervation of the cervical intervertebral discs. Spine (Phila Pa 1976) 1998;13(1):2-8.

4. Levine MJ, Albert TJ, Smith MD. Cervical Radiculopathy: Diagnosis and Nonoperative Management. J Am Acad Orthop Surg 1996;4(6):305-16.

5. Wallace D. Disc compression of the eighth cervical nerve: pseudo ulnar palsy. Surg Neurol 1982;18(4):295-9.

6. Rao R. Neck pain, cervical radiculopathy, and cervical myelopathy: pathophysiology, natural history, and clinical evaluation. J Bone Joint Surg Am 2002;84-A(10):1872-81.

7. Albert TJ, Murrell SE. Surgical management of cervical radiculopathy. J Am Acad Orthop Surg 1999;7(6):368-76.

8. Emery SE. Cervical spondylotic myelopathy: diagnosis and treatment. J Am Acad Orthop Surg 2001;9(6):376-88.

9. Ono K, Ebara S, Fuji T, Yonenobu K, Fujiwara K, Yamashita K. Myelopathy hand. New clinical signs of cervical cord damage. J Bone Joint Surg Br 1987;69(2):215-9.

10. Modic MT, Ross JS, Masaryk TJ. Imaging of degenerative disease of the cervical spine. Clin Orthop Relat Res 1989;(239):109-20.

11. Takahashi M, Yamashita $Y$, Sakamoto $Y$, Kojima R. Chronic cervical cord compression: clinical significance of increased signal intensity on MR images. Radiology 1989;173(1):21924. Crossref

12. Simmons Z, Biller J, Beck DW, Keyes W. Painless compressive cervical myelopathy with false localizing sensory findings. Spine (Phila Pa 1976) 1986;11(9):869-72.

13. Dwyer A, Aprill C, Bogduk N. Cervical zygapophyseal joint pain patterns. I: A study in normal volunteers. Spine (Phila $\mathrm{Pa}$ 1976) 1990;15(6):453-7.

14. Gorski JM, Schwartz LH. Shoulder impingement presenting as neck pain. J Bone Joint Surg Am 2003;85-A(4):635-8.

15. Hawkins RJ, Bilco T, Bonutti P. Cervical spine and shoulder pain. Clin Orthop Relat Res 1990;(258):142-6.

16. Rhee JM, Yoon T, Riew KD. Cervical radiculopathy. J Am Acad Orthop Surg 2007;15(8):486-94.

17. Pollack EW. Surgical anatomy of the thoracic outlet syndrome. Surg Gynecol Obstet 1980;150(1):97-103. 
18. Jellinger K. Spinal cord arteriosclerosis and progressive vascular myelopathy. J Neurol Neurosurg Psychiatry 1967;30(3):195-206.

19. Rothman $\mathrm{RH}$, Simeone FA, editors. The spine, 2nd ed. Philadelphia: WB Saunders \& Co.; 1982.

20. Cummins CA, Messer TM, Nuber GW. Suprascapular nerve entrapment. J Bone Joint Surg Am 2000;82(3):415-24.

21. Santavirta $S$, Slätis $P$, Kankaanpää $U$, Sandelin J, Laasonen E. Treatment of the cervical spine in rheumatoid arthritis. J Bone Joint Surg Am 1988;70(5):658-67.
22. Spinner M. The anterior interosseous-nerve syndrome, with special attention to its variations. J Bone Joint Surg Am 1970;52(1):84-94.

23. Singh V, Andrea M, Trescot MD. Ulnar Nerve Entrapment. In: Andrea M, Trescot MD, editors. Peripheral Nerve Entrapments. Springer International Publishing; 2016. p. 383-96. 